\title{
Wind Potential Assessment Analysis of Jhampir, District Thatta Sindh, Pakistan
}

\author{
AFTAB AHMED*, FAREED HUSSAIN MANGI*, YASIR FAZLANI*,ATHAR CHACHAR*, AND KASHIF KHAN** \\ RECEIVED ON 29.03.2018 ACCEPTED ON 17.08.2018
}

\begin{abstract}
Wind potential analysis is analyzing how much wind energy is available in particular region. It is most important step because the economics of project depends on the site wind resources. Wind plant depends on the variation of long-term mean wind speed and other characteristics which vary from a distance to distance. This study discusses the wind speed characteristics and wind potential analysis using three years 2014-2016 wind data of Jhampir located in district Thatta, situated in the Southeast of Sindh province. The numerical Weibull distribution approach is used to estimate parameters. The correct estimation of wind parameters and class is essential before developing any wind project in the region. The data used in this study is measured at $80 \mathrm{~m}$ height. The region is classified as from class 1-7. The results show that monthly mean speed values lie between $4.79-10.96 \mathrm{~m} / \mathrm{s}$. The annual mean scale and shape parameters lie in the range of 7.42-7.59. The wind power density was found in a range of 303.31355.64. This study is related to the decision-making process on a significant wind project in Thatta or nearby region. The stable wind energy pattern is observed in the region for harnessing wind energy almost throughout the year. The Weibull probability density curves also indicate a trend of a boost in the chances of observing wind from 2014-2016.
\end{abstract}

Key Words: Weibull, Energy Potential, Monthly Wind, Energy Density.

\section{INTRODUCTION}

$\mathrm{P}$ akistan is currently facing severe energy crises due to distribution losses, Mismanagement of resources and so on. Most of the power produced in Pakistan is from fossil fuel or hydel sector, only $3 \%$ share is from the renewable energy source [1]. Depletion of natural resources like fossil fuel and climate change are serious issues that have major impacts on the economic and social development of countries.
Renewable energy sources like wind can provide an opportunity to promote sustainable development and therefore reduce dependency on fossil fuel-based energy [2]. Renewable energy share has increased around the globe during last 4 or 5 years due to overall cost reduction of the wind and solar equipment that has ultimately put the wind and solar in a competitive position to other more economic sources available in the market [3].

Authors E-Mail: (aftab.mere17@iba-suk.edu.pk, fareed.mangi@iba-suk.edu.pk, yasir.mere17@iba-suk.edu.pk, athar.mere17@iba-suk.edu.pk, 12te88@student.muet.edu.pk)

* Department of Energy System Engineering, Sukkur IBA University, Sukkur, Pakistan.

** Institute of Environmental Engineering \& Management, Mehran University of Engineering \& Technology, Jamshoro, Pakistan.

This is an open access article published by Mehran University Research Journal of Engineering and Technology, Jamshoro under the CC by 4.0 International License. 
The aim of this paper is to estimate wind potential of Region Nonetheless, wind turbine installation in each site is viable only after accurate analysis of site feasibility. It is necessary to conduct a feasibility study for installing turbines before any major decision by authorities [4].

Jhampir to add more wind turbines in the region, located in the southwest of Sindh province. For that, Weibull distribution is used to analyze characteristics of wind using the wind data for a period of 2014, 2015 and 2016 at height of $10 \mathrm{~m}$. Weibull distribution is chosen because it is a most widely used method for wind data analysis. Other methods such as Rayleigh distribution is also used but it is single parameters function and Weibull gives a better fit than Rayleigh distribution. This data may be extrapolated to 20 and $30 \mathrm{~m}$ height for lower altitude velocity. The yearly mean wind velocity for Jhampir is 7.5 $\mathrm{m} / \mathrm{s}$ which is suitable for wind turbines because wind turbine usually operates between $6-25 \mathrm{~m} / \mathrm{s}$. The extrapolation of data will help in analyzing the data at higher altitude and we know that as we go higher velocity and wind density tends to increase [5]. Few wind farms have been installed in the region selected for this study but still, this areas requires more study of wind potential in order to the accurate sitting of future turbines. Further, more accurate sitting of turbines helps in reducing negative environmental impacts of wind turbines with proper wind data characterization.

\subsection{Wind Data}

Data was obtained from Jhampir wind power plant located $120 \mathrm{~km}$ northeast of Karachi (District Thatta) at $250^{\circ} 01^{\prime} \mathrm{N}$ $60^{\circ} 01^{\prime} \mathrm{E}$ Sindh for the period of 2014, 2015 and 2016. The data was measured at height of $80 \mathrm{~m}$.

\section{STUDY REGION GEOGRAPHY}

Sindh is one of four provinces of Pakistan, and it has more than 500-kilometer coastal range and huge wind corridor. The Thatta city is located in the southwest of Sindh province Fig. 1 and Table 1 [6].

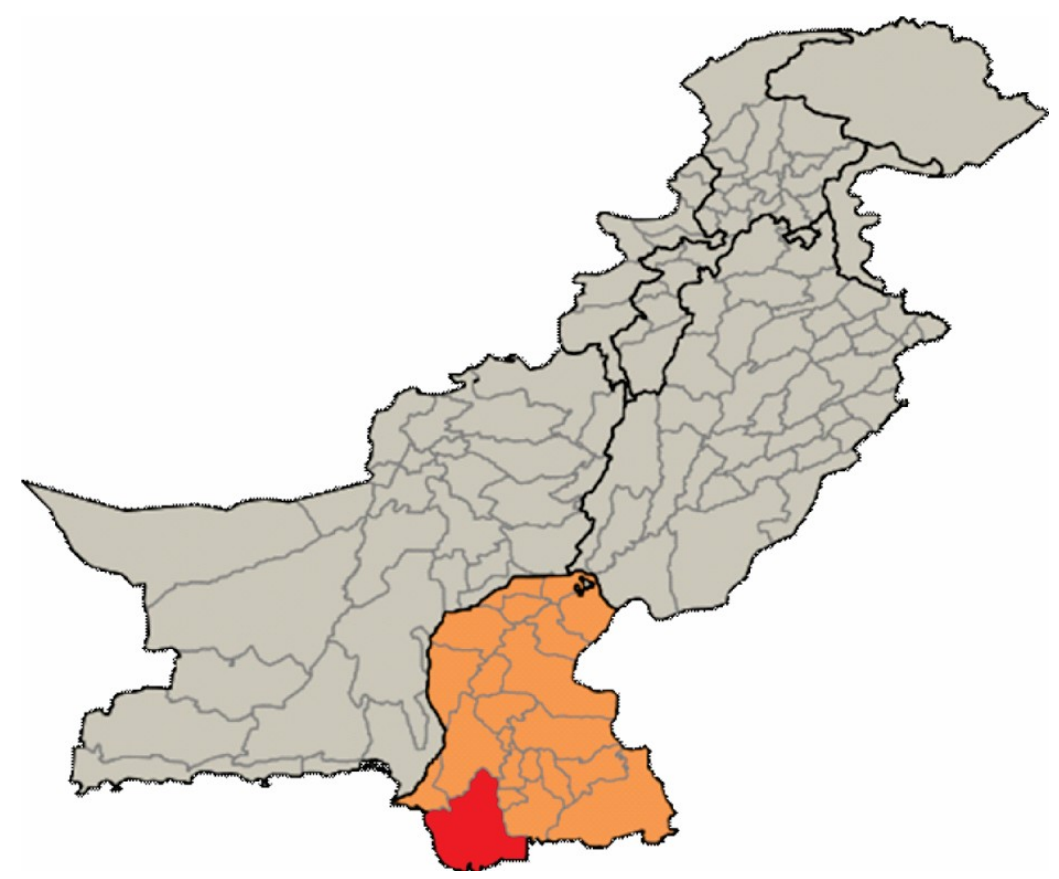

FIG. 1. MAP OF PAKISTAN INCLUDING STUDY REGION IN SINDH PROVINCE HIGHLIGHTED IN RED COLOR 


\section{METHODOLOGY}

Analysis of wind data can be performed using Rayleigh and Weibull distribution functions. Raleigh is one parameter function and less accurate than Weibull function. So in this study Weibull distribution is chosen for analysis of wind potential assessment of Jhampir, Thatta [7].

\subsection{Weibull Distribution Function}

Wind velocity distribution study is a critical aspect to evaluate wind energy potential for a location [8]. In Weibull function, the discrepancy in the wind velocity is characterized by two functions which are PDF (Probability Density Function) and CDF (Cumulative Distribution Function) respectively [8-9]. This is a twoparameter form of Weibull distribution. Depending on values of scale and shape parameters Weibull distribution can be used to model different behaviors. The PDF can take a variety of shapes based on values of shape parameter.

$$
\begin{aligned}
& f(v)=\frac{k}{c}\left(\frac{v}{c}\right)^{k-1} e^{-\left(\frac{v}{c}\right)^{k}} \\
& F(v)=1-\exp -\left(\frac{v^{k}}{c}\right)
\end{aligned}
$$

Where $f(v)$ is the probability of occurrence of gust, $v$ is velocity, $\mathrm{k}$ is dimensionless shape factor which shows wind velocity stability and is related to the variance of wind speed. The Shape parameter is also known as Weibull slope. The higher the value of $\mathrm{k}$ higher would be the stability of wind speed at given location. Where $\mathrm{c}$ is scale parameter (with units of wind velocity) and it is related to mean wind speed. Higher the value of $\mathrm{c}$ indicated that wind speed for that month is higher [9-10].

These Weibull parameters can be found using several methods, in this study the two methods Empirical and Energy pattern factor method is chosen [11]. Both of these methods consist of simple calcualtions and give more reasonable values. Empirical and Epf methods are used

TABLE 1. WIND MONTHLY MEAN SPEED DATA FOR THE YEAR 2014-2016

\begin{tabular}{|c|c|c|c|}
\hline Month & 2014 & 2015 & 2016 \\
\hline January & 6.20 & 6.13 & 5.47 \\
\hline February & 5.60 & 7.00 & 6.85 \\
\hline March & 5.90 & 6.32 & 7.59 \\
\hline April & 6.80 & 7.48 & 10.96 \\
\hline May & 8.40 & 9.16 & 10.21 \\
\hline June & 10.62 & 7.83 & 10.47 \\
\hline July & 10.64 & 10.79 & 8.11 \\
\hline August & 9.01 & 10.28 & 9.08 \\
\hline September & 9.11 & 7.48 & 5.85 \\
\hline October & 5.59 & 6.57 & 4.87 \\
\hline November & 5.47 & 6.59 & 4.79 \\
\hline December & 5.74 & 5.45 & \\
\hline
\end{tabular}

Mehran University Research Journal of Engineering \& Technology, Volume 38, No. 3, July, 2019 [p-ISSN: 0254-7821, e-ISSN: 2413-7219] 
to calculate scale and shape parameters which is a requirement for probability density function of Weibull distribution. Both of these methods are more simple and elegant compared to others methods [11-12].

\subsubsection{Empirical Method}

The empirical approach is regarded as a special case of moment method, where Weibull parameters $\mathrm{k}$ and $\mathrm{c}$ are given as [12]:

$$
\begin{gathered}
k=\left(\frac{\sigma}{\bar{v}}\right)_{\bar{v}}^{-1.086} \\
c=\frac{\bar{v}}{\Gamma(1+1 / k)}
\end{gathered}
$$

\subsubsection{Energy Pattern Factor Method}

Energy pattern factor approach is the newly developed process by Ali Akdag (2009) and it has much simpler formulation than another method to calculate Weibull parameters. Equations of Energy pattern factor method are given as [13]:

$$
\begin{aligned}
& \text { Epf }=\frac{v^{3^{-}}}{\frac{v}{v}} \\
& k=1+\frac{3.69}{e p f^{2}} \\
& c=\frac{-}{\Gamma(1+1 / k)}
\end{aligned}
$$

Standard deviation and power density can be described mathematically as:

$$
\sigma^{2}=\frac{1}{n} \sum_{i=1}^{n}(V i-\bar{v})
$$

$$
\mathrm{E}=\frac{1}{2} \ell \times \mathrm{c}^{3}\left(1+\frac{3}{\mathrm{k}}\right)
$$

\section{SELECTION OF WIND TURBINE}

Even if we know that particular site has good wind resource, the selection of wind turbine is still challenging task. Wind turbines are designed according to windresource and environmental conditions. In low windareas wind turbineshave large rotors to capture more energy and in high wind regimes turbines have a smaller rotor but high rating generators [14].

Once the most apparent and maximum wind velocities are established, the wind turbine operating range can be predicted and is given by [15]:

$v_{\max \leq v_{c o}} \leq(2-10) v_{\max }(1.5-3) v_{\text {in }} \leq v_{\text {rated }}(2-4) \leq v_{\text {in }} 0.3 v_{\text {in }} \leq v_{c i} \leq 0.8 v_{m p}$ (10)

Where $v_{c o}$ is wind velocity at which the wind turbine shuts down (cut-out wind velocity) $v_{c i}$ is the wind velocity at which wind turbine starts to produce power known as cut in wind velocity and $v_{\text {rated }}$ is the wind velocity at which wind turbine runs at full rating. The power output potential curve of a wind turbine differ from one turbine to other [16-17] (Table 2).

\section{RESULTS AND DISCUSSION}

In this study, Three years of Monthly mean wind speed data (2014-2016) at height of $80 \mathrm{~m}$ have been analyzed. It was found that maximum and minimum monthly wind speed were 10.96 and 4.87 . The annual mean wind speed maximum and minimum values are 7.59 and 7.42 respectively. The wind power values are in the range of 1116 and $93 \mathrm{~kW}$. The results indicate that maximum power isavailable in the months of May, June, July, and August, while minimum power is available in December and January (Table 3). 
The scale and shape parameter are calculated using Empirical and Epf Methods are given in Table 4. The results indicate that using Empirical Method values of Shape parameter lies between 5.17 and 3.67, while scale parameter value are in the range of 8.28 and 8.17 . The values of Shape and Scale parameter calculated using Epf method are also given in Table 4. These values of Shape parameter clearly indicate smooth wind flow pattern in Jhampir. The scale parameter values show that Jhampir is quite good windy location.

TABLE 2. WIND DATA CLASSIFICATION AT 80M HEIGHT

\begin{tabular}{|c|c|c|c|c|}
\hline \multicolumn{2}{|c|}{ Wind Power Classification } & $\begin{array}{l}\text { Wind Power Density } \\
\qquad(\mathrm{W} / \mathrm{m} 2)\end{array}$ & $\begin{array}{c}\text { Mean Wind Speed } \\
(\mathrm{m} / \mathrm{s})\end{array}$ & Resource Potential \\
\hline \multirow{2}{*}{1} & $1-$ & \multirow{2}{*}{$0.0-\quad 200$} & \multirow{2}{*}{$0.0-5.9$} & \multirow{2}{*}{ Very poor } \\
\hline & $1+$ & & & \\
\hline \multirow{2}{*}{2} & $2-$ & \multirow{2}{*}{$200-300$} & \multirow{2}{*}{$5.9-6.9$} & \multirow{2}{*}{ Poor } \\
\hline & $2+$ & & & \\
\hline \multirow{2}{*}{3} & $3-$ & \multirow{2}{*}{$300-400$} & \multirow{2}{*}{$6.9-7.5$} & \multirow{2}{*}{ Marginal } \\
\hline & $3+$ & & & \\
\hline \multirow{2}{*}{4} & $4-$ & \multirow{2}{*}{$400-500$} & \multirow{2}{*}{$7.5-8.1$} & \multirow{2}{*}{ Good } \\
\hline & $4+$ & & & \\
\hline \multirow{2}{*}{5} & $5-$ & \multirow{2}{*}{$500-600$} & \multirow{2}{*}{$8.1-8.6$} & \multirow{2}{*}{ Very Good } \\
\hline & $5+$ & & & \\
\hline \multirow{2}{*}{6} & 6- & \multirow{2}{*}{$600-700$} & \multirow{2}{*}{$8.6-9.4$} & \multirow{2}{*}{ Excellent } \\
\hline & $6+$ & & & \\
\hline \multirow{2}{*}{7} & $7-$ & \multirow{2}{*}{$700-805$} & \multirow{2}{*}{$? 9.4$} & \multirow{2}{*}{ Very Excellent } \\
\hline & $7+$ & & & \\
\hline
\end{tabular}

TABLE 3. POWER AVAILABLE IN YEAR 2014-2016

\begin{tabular}{|c|c|c|c|}
\hline Months & Power 2014 (KW) & Power 2015 (KW) & Power 2016 (KW) \\
\hline January & 202.17 & 195.33 & 138.78 \\
\hline February & 148.97 & 290.86 & 228.60 \\
\hline March & 174.22 & 214.66 & 370.78 \\
\hline April & 266.67 & 354.89 & 1116.41 \\
\hline May & 502.69 & 651.75 & 902.55 \\
\hline June & 1015.86 & 407.08 & 973.27 \\
\hline July & 1021.45 & 1065.27 & 452.33 \\
\hline August & 620.45 & 921.89 & 634.82 \\
\hline September & 641.35 & 354.39 & 169.77 \\
\hline October & 148.12 & 557.13 & 97.94 \\
\hline November & 138.78 & 242.69 & 93.19 \\
\hline December & 160.37 & 137.27 & 445.68 \\
\hline Average & 420.19 & 449.43 & \\
\hline
\end{tabular}

TABLE 4. SCALE AND SHAPE PARAMETERS OF THE WEIBULL DISTRIBUTION

\begin{tabular}{|c|c|c|c|c|c|}
\hline Year & k Empirical & c Empirical & kEpf & cEpf & Annual Mean \\
\hline 2014 & 4.13 & 8.17 & 3.26 & 8.27 & 7.42 \\
\hline 2015 & 5.17 & 8.25 & 3.65 & 8.40 & 7.59 \\
\hline 2016 & 3.67 & 8.28 & 4.00 & 8.24 & 7.47 \\
\hline
\end{tabular}

Mehran University Research Journal of Engineering \& Technology, Volume 38, No. 3, July, 2019 [p-ISSN: 0254-7821, e-ISSN: 2413-7219] 
The Fig. 2 clearly indicates that the monthly mean wind speed is higher during the months of May, June, July, and August and lower during the months November, December, and January.

Fig. 3(a-c) demonstrates the Weibull distribution and wind speed model justification. It clearly indicates that wind speed values are quite close and fit well with Weibull distribution. Fig. 3(a-c) also indicates data validation for chosen method. The more align the data with a straight line more suitable is a method to analyze given data.

Fig. 4(a-b) shows the probability density function and wind velocity which is drawn by using the values from Scale and Shape parameter. These dimensionless parameters are resolved using Empirical and Epf methods. The Probability density function curves clearly indicate a boost in the probability of witnessing higher wind velocities from 2014-2016. This trend illustrates that higher wind velocities have been experienced in previous three years. The probability density curve shows higher probability density for the year 2015 in Fig. 4(a). However, it is higher for the year 2016 in Fig. 4(b). Hence it is concluded that both methods show a significant increase in chances of wind for given region. In probability density curves both Empirical and Epf method show, 7-8 m/s having a maximum frequency which is more than required average wind speed for any site selection.

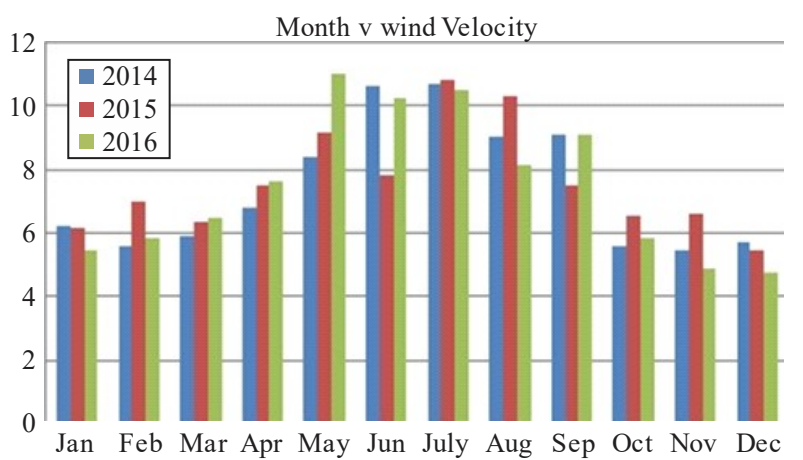

FIG. 2. MONTHLY MEAN WIND SPEED VARIATIONS

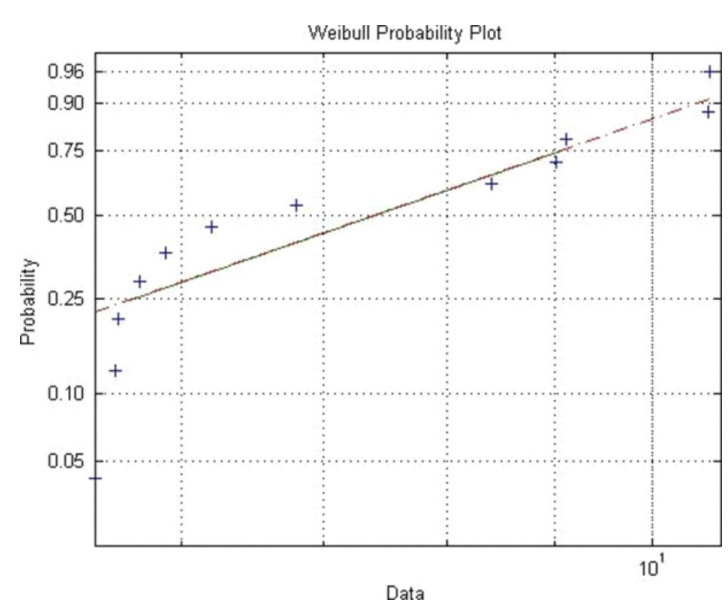

FIG. 3(a). SHOWING DATA FITNESS USING WEIBULL PROBABILITY PLOT FOR THE YEAR 2014

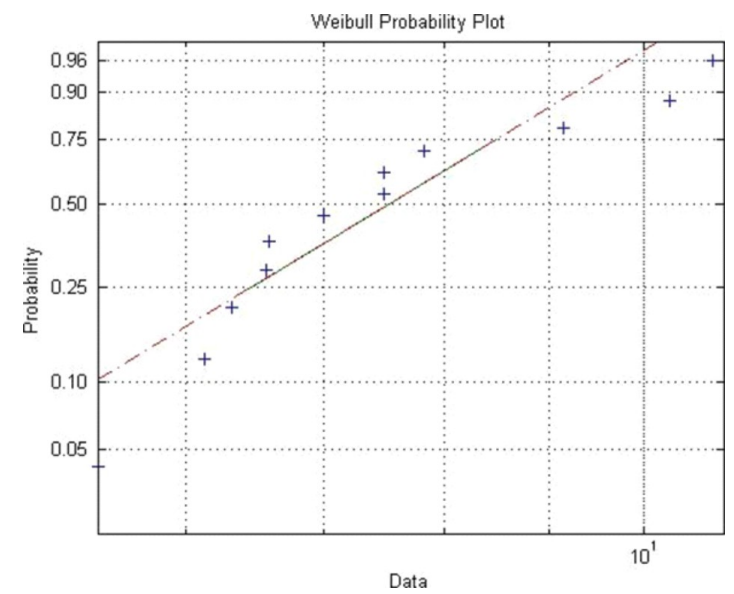

FIG. 3(b).SHOWING DATA FITNESS USING WEIBULL PROBABILITY PLOT FOR THE YEAR 2015

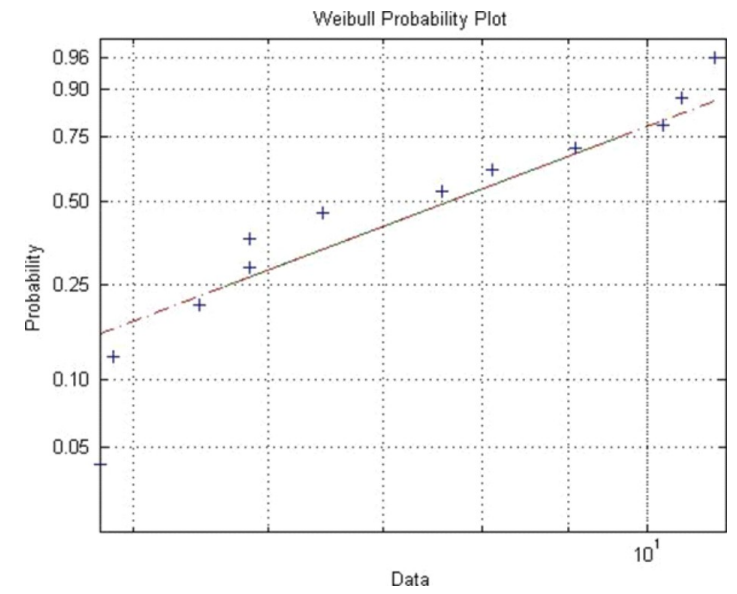

FIG. 3(c). SHOWING DATA FITNESS USING WEIBULL PROBABILITY PLOT FOR THE YEAR 2016

Mehran University Research Journal of Engineering \& Technology, Volume 38, No. 3, July, 2019 [p-ISSN: 0254-7821, e-ISSN: 2413-7219] 
The wind power density or Energy density values lie in the range of $355.64-303.31 \mathrm{w} / \mathrm{m}^{2}$. These values show that there is suitable wind energy present in the Jhampir location (Table 5).

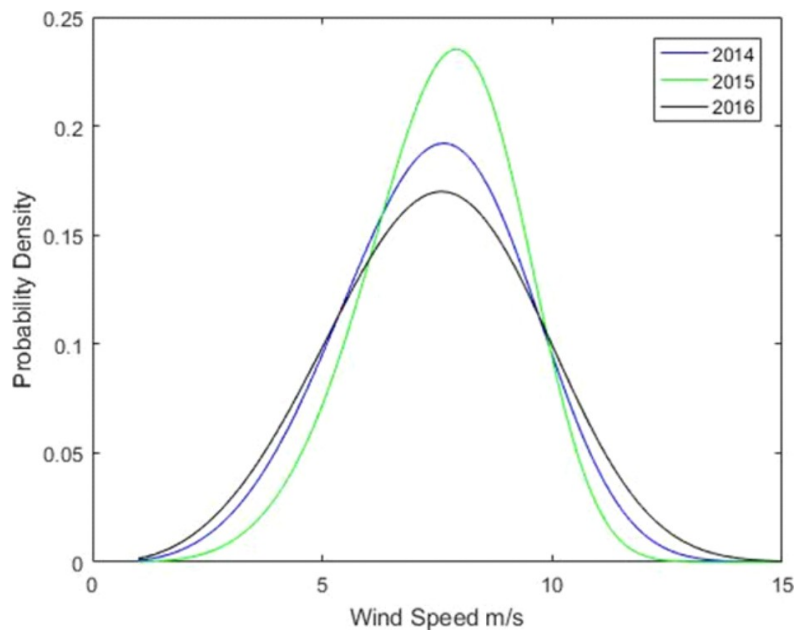

FIG. 4(a). PROBABILITY DENSITY FUNCTION FOR WIND SPEED USING THE EMPIRICAL METHOD

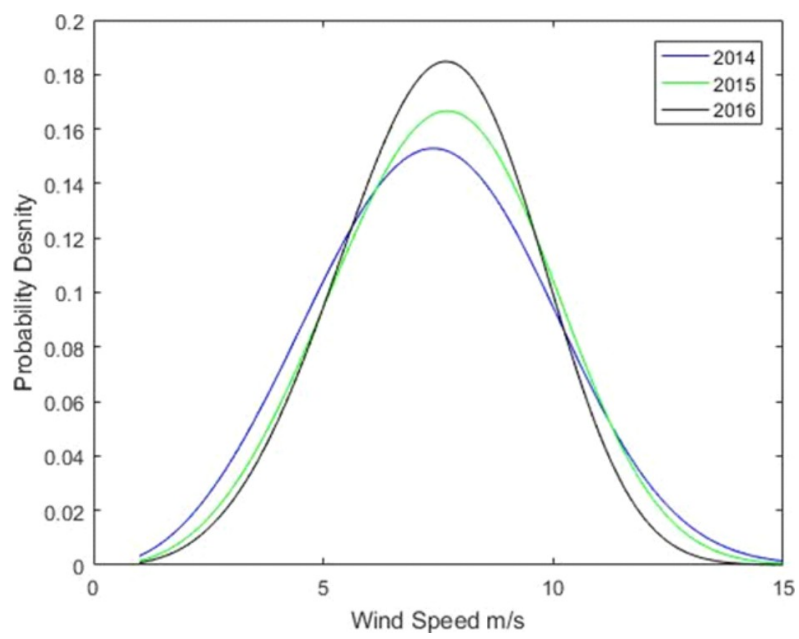

FIG. 4(b). PROBABILITY DENSITY FUNCTION FOR WIND SPEED USING EPF METHOD
The average of annual mean wind speed value is 7.50 Which indicates that Jhampir is a quite good location for Generating Electricity from the wind and it lies in class 4. It is also perceived that trend in annual mean wind velocity is linear and Annual power density values of both methods are also close to each other.

The Fig. 5(a-c) shows combine commulative density based on annual mean wind speed values. The cumulative plot for each year show combine effect of wind speed on probability density. It is clear from the plot that after wind speed reaches the mark of $15 \mathrm{~m} / \mathrm{s}$ cumulative density remain same with an increase in wind speed. Studying the substantial wind velocity frequency distribution of the region with a fitting model of wind energy conversionsystem can enhance the energy output [18]. Therefore a wind energy conversion system can run at theoptimum output only if it is devised for the region where it is to be applied, as rated power, and cut in, rated and cut off wind speeds must be characterized according to region [19-20].

\section{CONCLUSION}

In this study, three years of wind data (2014-2016) have been analyzed. The Weibull function was adopted to interpret the data. The monthly and annual mean wind velocity revealed a good stable wind pattern. The mean annual mean wind speed was 7.5 which ultimately puts

TABLE 5. WIND POWER DENSITY VALUES USING EMPIRICAL AND EPF METHOD.

\begin{tabular}{|c|c|c|}
\hline Year & $\begin{array}{c}\text { Wind Power Density w/m } \\
\text { (Empirical) }\end{array}$ & $\begin{array}{c}\text { Wind Power Density w/m } \\
\text { (Epf) }\end{array}$ \\
\hline 2014 & 355.64 & 303.31 \\
\hline 2015 & 327.37 & 314.09 \\
\hline 2016 & 331.40 & 313.63 \\
\hline
\end{tabular}


Jhampir in class 4 among wind classes. The higher values of scale parameter also indicate that Jhampir is quite good windy location. The shape parameter obtained by both Empirical and Epf method is also high and shows stable wind pattern in Jhampir.

The available power in the wind and Energy density values illustrate that there is enough wind potential available in Jhampir. Thus results obtained from this study strengthen the idea of the installation of more wind turbines in Jhampir for generation of electricity.

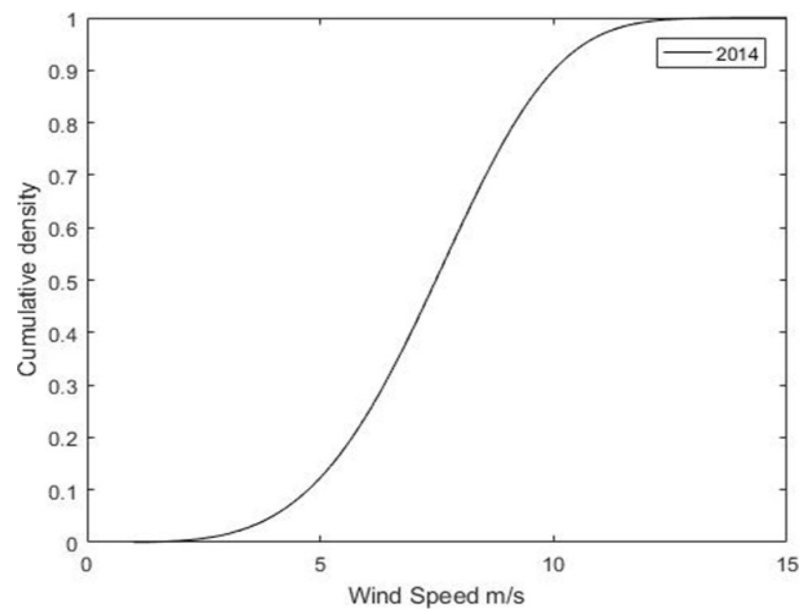

FIG. 5(a). CUMULATIVE WEIBULL DISTRIBUTION OF JHAMPIR FOR THE YEAR 2014

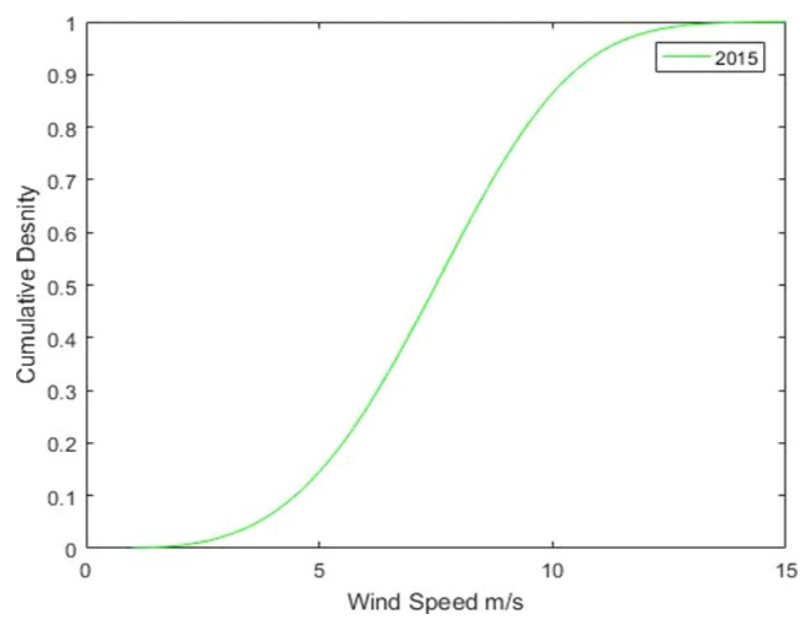

FIG. 5(b). CUMULATIVE WEIBULL DISTRIBUTION OF JHAMPIR FOR THE YEAR 2015

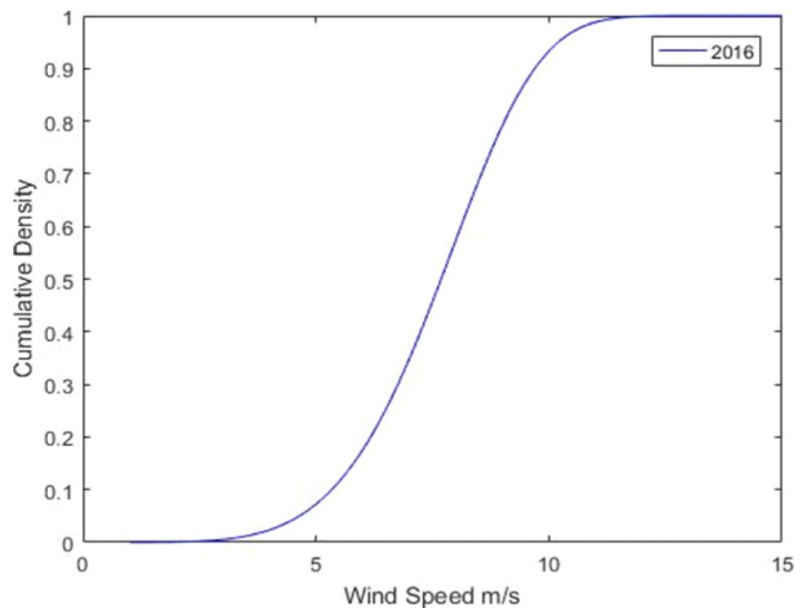

FIG. 5(c). CUMULATIVE WEIBULL DISTRIBUTION OF JHAMPIR FOR THE YEAR 2016

\section{NOMENCLATURE}

$\mathrm{F}(\mathrm{v})$ Cumulative distribution function

c scale parameter

$f(\mathrm{v}) \quad$ Probability density function

k Shape factor

$1 / 2$ " Monthly mean Wind speed

\section{Greek Symbols}

$\Gamma \quad$ Gamma function

$1 \quad$ Air density $\left(\mathrm{kg} / \mathrm{m}^{3}\right)$

$\sigma \quad$ Standard deviation

\section{ACKNOWLEDGEMENT}

The authors are very thankful to respected viewers for their valuable comments. Authors also show gratitude for the Jhampir wind farm for providing three years of data. 


\section{REFERENCES}

[1] Mohammadi, K., and Mostafaeipour A., "Economic Feasibility of Developing Wind Turbines in Aligoodarz, Iran”, Energy Conversion and Management, Volume 76, pp. 645-653, 2013.

[2] Carneiro, F.M., Rocha, H.B., and Rocha, P.C., "Investigation of Possible Societal Risk Associated with Wind Power Generation Systems", Renewable and Sustainable Energy Reviews, Volume 19, pp. 30-36, 2013.

Ahmed, M.A., Ahmed, F., and Akhtar, M.W., "Wind Characteristics and Wind Power Potential for Southern Coasts of Sindh, Pakistan", Journal of Basic \& Applied Sciences, Volume 6, 2010.

[4] Ahmed, S.A., "Comparative Study of Four Methods for Estimating Weibull Parameters for Halabja, Iraq", International Journal of Physical Sciences, Volume 8, pp. 186-192, 2013.

[5] Khurho, A.A., and. Soomro, B.A., "A Comparison between Empirical and Epf Method for Wind Data Analysis", Proceedings of IEE 7th International Mechanical Engineering Conference, NED University of Engineering \& Technology, Karachi, Pakistan, 2017

Rocha, P.A.C., de Sousa, R.C., de Andrade, C.F., and da Silva, M.E.V., "Comparison of Seven Numerical Methods for Determining Weibull Parameters for Wind Energy Generation in the Northeast Region of Brazil", Applied Energy, Volume 89, pp. 395-400, 2012.

Indhumathy, D., Seshaiah, C., and Sukkiramathi, K., "Estimation of Weibull Parameters for Wind Speed Calculation at Kanyakumari in India”, International Journal of Innovative Research in Science, Engineering, \& Technology, Volume 3, pp. 8340-8345, 2014.

Ayodele, T.R., Jimoh, A.A., Munda, J.L., and Agee, J.T., "Statistical Analysis of Wind Speed and Wind Power Potential of Port Elizabeth using Weibull Parameters", Journal of Energy in Southern Africa, Volume 23, pp. 30-38, 2012.
[9] Choge, D.K., Rotich, S.K., and Tonui, J.K., "Small Wind Turbines: A Simulation for Optimal Selection in UasinGishu, Kenya", Pacific Journal of Science and Technology, Volume 14, pp. 102-108, 2013.

[10] Jang, J.-K., Yu, B.-M., Ryu, K.-W., and Lee, J.-S., "Offshore Wind Resource Assessment Around Korean Peninsula by using QuikSCAT Satellite Data", Journal of the Korean Society for Aeronautical \& Space Sciences, Volume 37, pp. 1121-1130, 2009.

[11] Chaurasiya, P.K., Ahmed, S., and Warudkar, V., "Comparative Analysis of Weibull Parameters for Wind Data Measured from Met-Mast and Remote Sensing Techniques. Renewable Energy, Volume 115, pp. 1153-1165, 2018.

[12] Kim, H., and Kim, B., "Wind Resource Assessment and Comparative Economic Analysis using AMOS Data on a 30 MW Wind Farm at Yulchon District in Korea", Renewable Energy, Volume 85, pp. 96-103, 2016.

[13] Oh, K.-Y., Kim, J.-Y., Lee, J.-S., and Ryu, K.-W., "Wind Resource Assessment Around Korean Peninsula for a Feasibility Study on 100 MW Class Offshore Wind Farm”, Renewable Energy, Volume 42, pp. 217-226, 2012.

[14] Carta, J.A., Ramirez, P., and Velazquez, S., "A Review of Wind Speed Probability Distributions Used in Wind Energy Analysis: Case Studies in the Canary Islands”, Renewable and Sustainable Energy Reviews, Volume 13, pp. 933-955, 2009.

[15] Shu, Z., Li, Q., and Chan, P., "Statistical Analysis of Wind Characteristics and Wind Energy Potential in Hong Kong”, Energy Conversion and Management, Volume 101, pp. 644-657, 2015.

[16] Engström, S., Lyrner, T., Hassanzadeh, M., Stalin, T., and Johansson, J., "Tall Towers for Large Wind Turbines", Report from Vindforsk Project, Volume 342, pp. 50, 2010. 
[17] Min, C.-G., Park, J.K., Hur, D. and Kim, M.-K., "The Economic Viability of Renewable Portfolio Standard Support for Offshore Wind Farm Projects in Korea", Energies, Volume 8, pp. 9731-9750, 2015.

[18] Corotis, R.B., Sigl, A.B., and Klein, J., "Probability Models of Wind Velocity Magnitude and Persistence", Solar Energy, Volume 20, pp. 483-493, 1978.
Boudia, S.M., Benmansour, A., and Tabet, H.M.A., "Wind Energy Resource Assessment at Tindouf Region, Extreme Southwest of Algeria", Applied Mechanics \& Materials, Trans Tech Publications, Volume 541, pp. 972-976, 2014.

[20] Oh, K.-Y., Kim, J.-Y., Lee, J.-K., Ryu, M.-S., and Lee, J.-S., "An Assessment of Wind Energy Potential at the Demonstration Offshore Wind Farm in Korea", Energy, Volume 46, pp. 555-563, 2012. 